\title{
Prediction of Properties of Sclerolobium paniculatum and Qualea grandiflora Charcoal
}

\author{
Teddy Diogo Rios Terra ${ }^{1}$ (D), Renato da Silva Vieira ${ }^{2}$ (D), \\ Edy Eime Pereira Baraúna ${ }^{3}$ \\ ${ }^{1}$ Universidade Federal do Tocantins - UFT, Gurupi/TO, Brasil \\ ${ }^{2}$ Universidade Federal de São João Del Rei - UFS, Sete Lagoas/MG, Brasil \\ ${ }^{3}$ Universidade Federal de Minas Gerais - UFMG, Montes Claros/MG, Brasil
}

\begin{abstract}
There is a lack of techniques for the rapid and accurate determination of wood quality for charcoal production with good energy characteristics. The association of NIR spectroscopy and important charcoal parameters allows the prediction of these characteristics. This is a fast method that does not require sample preparation before the reading. The spectral readings were performed with solid and ground samples, and presented the second best representation of the evaluated parameters. Data went was adjusted to correct for variations that could occur during the spectra reading. The treatment with the best results was the normal transformation of variation. The evaluated spectra were able to explain $77 \%$ of the data for the variable gravimetric yield, $88 \%$ for volatile materials content and $86 \%$ for fixed carbon content.
\end{abstract}

Keywords: NIR spectroscopy, wood quality, biomass energy. 


\section{INTRODUCTION}

Assessing wood quality is a key stage in genetic improvement programs and to determine the best use of this material. The chemical and anatomical components of wood present great variability, both among species and within the same individual. Determining and quantifying these components implies a laborious and time consuming process from the preparation of the samples to the results (Hein et al., 2016).

Near-infrared spectroscopy (NIRS) is an analytical technique that employs reading the molecular vibrations resulting from the incidence of an infrared ray on some compound or sample performed at a wavelength of 750 to $2500 \mathrm{~nm}$ (Pasquini, 2003). Variations in spectrum absorbance due to changes in the chemical composition of the elements can be quantified and used in several studies (Campos et al., 2009).

NIRS has proven to be an efficient and reliable method in the most varied forms of use, such as for characterization studies of wood quality (Duca et al., 2016). The technique can be used to identify molecular species in complex chemical mixtures, such as wood (Viana et al., 2009; Terdwongworakul et al., 2005). At the beginning of its application in the forestry sector, this application was more common in the pulp and paper industry segment due to the advancement and promotion of studies in this area (Nisgoski et al., 2016; Samistraro et al., 2009). However, many studies have been produced in several areas of wood technology such as charcoal and wood chemistry, among others (Ramalho et al., 2017; Duca et al., 2016; Meder et al., 2017).

Readings of the electromagnetic radiation in the NIRS range can be performed in samples with almost no previous preparation, allowing for qualitative and quantitative analyses of the wood without the need of felling the tree, thus constituting a non-destructive method (Schimleck et al., 2004). However, the application of this technique requires a database with reference values obtained by traditional methods for calibrating and validating the results found by this technique.

Due to the variability of the reading spectra, they need to undergo corrections through mathematical models in order to minimize reading errors (Williams \& Norris, 2001). In this context, the use of near-infrared spectroscopy (NIRS) represents a fast, reliable and inexpensive analytical method. When combined with multivariate analysis, it can correlate a variable of interest with the obtained spectra. This method is fast, taking about 90 seconds to carry out an analysis, in addition to having the advantage of not using any chemical substances and an almost total independence of operator errors.

The application of this technique to Brazilian cerrado species lies is important due to the large amount of commercialized charcoal coming from this biome. It is also important for the identification of cerrado species with potential to produce charcoal. This will contribute to the implantation of pure plantations to reduce pressure on species that do not have characteristics for this purpose.

Wood from the Sclerolobium paniculatum Vogel and Qualea grandiflora Mart. species are widely used for charcoal production and present rapid growth in regions of low soil fertility and large water deficit. Due to these characteristics, it is justifiable to study them as energy potential.

Thus, this study aimed to evaluate the feasibility of using NIRS for determining gravimetric yield, ash content, volatile materials and fixed carbon from the coal obtained from Sclerolobium paniculatum Vogel and Qualea grandiflora Mart., which are typical pioneering species of the sensu stricto cerrado.

\section{MATERIAL AND METHODS}

Sclerolobium paniculatum Vogel and Qualea grandiflora Mart. trees were collected from a suppression area for pasture maintenance in the municipalities of Gurupi-TO and Dueré-TO, with an average age of 7 years. Age was estimated as a function of the last suppression performed for pasture maintenance. Four individuals of each species were randomly selected taking into account the presence of heartwood (detected macroscopically) and DBH between 15 and $19 \mathrm{~cm}$.

We used Eucalyptus wood as comparison, since there are many studies on this species. Therefore, four (4) samples of Eucalyptus sp. obtained from a commercial plantation located in the municipality of Gurupi-TO, with 5 years of age and mean DBH of $23 \mathrm{~cm}$ were used as controls. 


\subsection{Sample acquisition}

The trees were felled at ground level and a $5.0 \mathrm{~cm}$ thick disc was removed from the base of each tree trunk.

The discs were divided into three positions external, internal and central; next, $2.0 \mathrm{~cm}$ x $2.0 \mathrm{~cm} \mathrm{x}$ $5.0 \mathrm{~cm}$ specimens were removed from each position of the disc (Figure 1).

After preparation, the specimens were submitted to the NIR spectrometer for spectra acquisition. The specimens were subsequently grinded in a Wiley mill, and sieved in a $1 \mathrm{~mm}$ mesh sieve. The material that passed through this sieve was also submitted to the spectra acquisition. The spectral acquisition procedures were performed at CIRAD.

\subsection{Obtaining the spectra}

BRUKER $^{\circ}$ equipment with an integration sphere was used to obtain the spectra. We collected one spectrum per sample. Each spectrum was obtained from 32 and 64 scans in the range of 1100-2500 nm with a resolution of $8 \mathrm{~cm}^{-1}$, obtained from the radial side of the specimens in their original state (OS) and after being ground (GS) and sieved in a $1 \mathrm{~mm}$ mesh.

The specimens were conditioned in air-conditioned room with a relative humidity of $65 \%$ and temperature of $21^{\circ} \mathrm{C}$, thus giving the test specimens a moisture content of $12 \%$.

\subsection{Energy characterization}

For the energy characterization process, $6 \mathrm{~g}$ of totally dry sawdust $\left(103 \pm 2{ }^{\circ} \mathrm{C}\right)$ from each specimen were placed into a covered crucible in a muffle oven.

With the purpose of simulating the conventional carbonization process as close as possible, the carbonization rate was performed at $4.5^{\circ} \mathrm{C} /$ minute, taking 1 hour and 40 minutes to reach the temperature
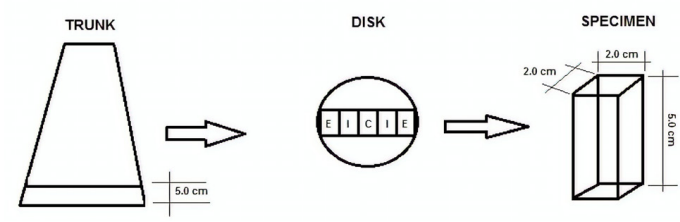

Figure 1. Scheme for obtaining the samples: (E) disk external position; (I) disc intermediate position and (C) disk center position. of $450{ }^{\circ} \mathrm{C}$, and remaining for another 30 minutes at this temperature. After the muffle oven cooled, the weight of the obtained coal was determined.

To determine the gravimetric yield (GY\%), the following equation was used: $G Y=\frac{D C W}{D W W} \times 100$

In which, GY\%: gravimetric yield; DWW: dry wood weight; DCW: dry charcoal weight $\left(103 \pm 2{ }^{\circ} \mathrm{C}\right)$.

The AFNOR 1860-2 standard (AFNOR, 2000) was used to determine the content of volatile materials (VMC), ash (AC) and fixed carbon (FCC) of the produced charcoal.

\subsection{Statistical analysis}

The experiment was conducted using a Random Block Design (RBD) under a $3 \times 3$ factorial arrangement (species $\mathrm{x}$ positions) with four replications. Data were submitted to transformation in arcsen $\sqrt{ }(x \div 100)$, since they did not comply with the principle of normal distribution. The results were submitted to analysis of variance by the $\mathrm{F}$ test at the $5 \%$ probability level to verify the effect of variability between species on gravimetric yield, content of volatile materials, ash content and fixed carbon content. When significant, differences were identified $(\mathrm{P}<0.05)$ and the comparative test between means at the $5 \%$ probability level was applied by the Tukey test. Statistical analyzes were performed using the Sisvar and Microsoft Office Excel 2010 programs.

\subsection{Pre-treatment of spectral data}

We acquired spectral data (reflectance intensity versus wavelength) using the Unscrambler 9.7 software by CAMO A.S., according to standard ASTME1655-05 (ASTM, 2000). In order to minimize variations of the spectral readings, which can affect the distribution and uniformity, the following normalization pre-treatments were tested. These tests are used to obtain the data with similar scales to obtain a more uniform distribution of the variances, and smoothing applied to the reduction of spectral noise: standard normal variation transformation (SNV) with 20-point window with quadratic adjustment; and Partial least squares regression (PLS) applied to the data matrix of the cross-validated samples (with the exception of the outliers) with the objective of correlating the spectra with the following variables: Gravimetric yield (GY), Volatile Materials Content (VMC), Fixed Carbon Content (FCC) and Ash Content (AC). 
The choice for the data pre-treatment was based on the coefficient of determination $\left(\mathrm{R}^{2}\right)$ that represents the adjustment measure of a generalized linear statistical model in relation to the observed values, indicating how much the model can explain the observed values. In addition to the determination coefficient, a correlation between the studied variables and the spectra was also adopted for the choice of pre-treatments, which portrays the accuracy of the model and allows for predicted error standardization, making it possible to compare different properties (Hein et al., 2010).

For the construction of the models, the range of all samples was considered to predict the variables for immediate charcoal chemistry and gravimetric yield due to the amount of samples obtained in this study.

\section{RESULTS AND DISCUSSION}

The following results were obtained from the energy evaluation, as presented in Table 1.

According to the data presented in Table 1, we observed a high gravimetric yield percentage of the species studied in relation to Eucalyptus sp.. We conclude that this high gravimetric yield, in addition to the low ash content found, shows superiority of the cerrado species in relation to the traditional species for charcoal production. This relationship was also observed by Vale et al. (2010), who studied the gravimetric yield of charcoal produced from cerrado species and found an average of $35 \%$. This difference may be associated with the $50 \%$ slower heating ramp in this study, which may increase the gravimetric yield. Table 2 shows the results of the calibration models for gravimetric yield.

Table 2 shows the gravimetric yield variable versus the calculated values, based on the NIRS spectra obtained from the wood, with the best coefficient of determination presented by standard normal variate transformation (SNV). Ground wood presented the best results.

The best coefficient of determination $\left(\mathrm{R}^{2}\right)$ found for calibration was higher than 0.7 for the ground wood (0.7711), with $87.38 \%$ correlation for powder samples with the GY variable, indicating a strong correlation between the variable and the spectrum. Andrade et al. (2012) found a coefficient of determination $\left(\mathrm{R}^{2}\right)$ of 0.74 with a correlation of $86 \%$ for the gravimetric yield variable in the prediction of wood and coal properties from clonal plantations of Eucalyptus sp. using near-infrared spectroscopy.

Table 3 shows that the volatile materials variable presented the highest coefficient of determination $\left(\mathrm{R}^{2}\right)$ among all analyzed variables, and the spectral readings of the ground samples showed the best determination coefficients $(0.88)$ by SNV data processing method (standard normal variation transformation). Campos et al.

Table 1. Averages obtained for the variables: GY, FCC, VMC and AC after the energetic evaluation of the studied wood.

\begin{tabular}{lcccc}
\multicolumn{1}{c}{ Species } & \%GY & \%FCC & \%VMC & \%AC \\
\hline Eucalyptus sp. & $24.90 \mathrm{Cb}$ & $79.14 \mathrm{Aa}$ & $19.10 \mathrm{Ca}$ & $1.75 \mathrm{Aa}$ \\
Qualea grandiflora Mart & $25.96 \mathrm{Ba}$ & $77.79 \mathrm{Aa}$ & $20.65 \mathrm{Ba}$ & $1.54 \mathrm{Ba}^{*}$ \\
Sclerolobium paniculatum Vogel & $29.56 \mathrm{Aa}$ & $72.05 \mathrm{Ba}$ & $26.38 \mathrm{Aa}$ & $1.56 \mathrm{Ba}$ \\
\hline
\end{tabular}

${ }^{*}$ Means followed by the same uppercase letter in the column and the same lowercase letter in the row do not differ at the $5 \%$ probability level by the Tukey test; GY: gravimetric yield; FCC: fixed carbon content; VMC: volatile materials content; AC: ashes content.

Table 2. Multivariate calibration model (PLS) for gravimetric yield.

\begin{tabular}{|cccccc}
\multirow{2}{*}{ Type of scans* } & Reference & Without & \multicolumn{3}{c|}{ Pre-treatments } \\
\cline { 4 - 6 } & values $^{* *}$ & Pretreatment & Smoothing & Normalization & SNV \\
\multirow{2}{*}{ Ground 64 scans } & $\mathrm{R}^{2}$ & 0.3023 & 0.3327 & 0.3378 & 0.7711 \\
& Correlation & 0.5415 & 0.5601 & 0.5710 & 0.8738 \\
\multirow{2}{*}{ Original 32 scans } & $\mathrm{R}^{2}$ & 0.7184 & 0.7254 & 0.7352 & 0.7437 \\
& Correlation & 0.8467 & 0.8509 & 0.8494 & 0.8589 \\
\hline
\end{tabular}

${ }^{*}$ Best results for each treatment of the specimens $\mathrm{x}$ number of scans; ${ }^{*}$ The reference values were determined by the coefficient of determination $\left(\mathrm{R}^{2}\right)$ and by the correlation between the spectra and the variable in question; PLS: Partial Least Squares; SNV: Standard Normal Variate. 
Table 3. Multivariate calibration model (PLS) of volatile materials.

\begin{tabular}{|cccccc}
\multirow{2}{*}{ Type of scans } & \multirow{2}{*}{$\begin{array}{c}\text { Reference } \\
\text { values }\end{array}$} & Without & \multicolumn{3}{c}{ Pre-treatments } \\
\cline { 4 - 6 } & $\mathrm{R}^{2}$ & 0.2842 & 0.2885 & 0.2940 & 0.8834 \\
\multirow{2}{*}{ Ground 64 scans } & Correlation & 0.5244 & 0.5307 & 0.5186 & 0.9377 \\
& $\mathrm{R}^{2}$ & 0.8547 & 0.8525 & 0.8511 & 0.8661 \\
\multirow{2}{*}{ Original 32 scans } & Correlation & 0.9204 & 0.9188 & 0.9189 & 0.9289 \\
\hline
\end{tabular}

${ }^{*}$ Best results for each treatment of the specimens x number of scans; ${ }^{* *}$ The reference values were determined by the coefficient of determination $\left(\mathrm{R}^{2}\right)$ and by the correlation between the spectra and the variable in question; PLS: Partial Least Squares; SNV: Standard Normal Variate.

Table 4. Multivariate calibration model (PLS) of fixed carbon.

\begin{tabular}{|cccccc}
\multirow{2}{*}{ Type of scans } & \multirow{2}{*}{$\begin{array}{c}\text { Reference } \\
\text { values** }\end{array}$} & Without & \multicolumn{3}{c}{ Pre-treatments } \\
\cline { 4 - 6 } & Pretreatment & Smoothing & Normalization & SNV \\
\hline \multirow{2}{*}{ Ground 64 scans } & $\mathrm{R}^{2}$ & 0.3011 & 0.2636 & 0.2617 & 0.8694 \\
& Correlation & 0.5342 & 0.5000 & 0.5012 & 0.9326 \\
\multirow{2}{*}{ Original 16 scans } & $\mathrm{R}^{2}$ & 0.8511 & 0.8521 & 0.8611 & 0.8638 \\
& Correlation & 0.9209 & 0.9227 & 0.9257 & 0.9282 \\
\hline
\end{tabular}

${ }^{*}$ Best results for each treatment of the specimens $\mathrm{x}$ number of scans; ${ }^{*}$ The reference values were determined by the coefficient of determination $\left(\mathrm{R}^{2}\right)$ and by the correlation between the spectra and the variable in question; PLS: Partial Least Squares; SNV: Standard Normal Variate.

(2008) found a coefficient of determination $\left(\mathrm{R}^{2}\right)$ varying from 0.83 to 0.96 in the prediction of the volatile material content of Eucalyptus sp. by near-infrared spectroscopy. This indicates a potential of the technique in the determination of volatile material in charcoal samples. Table 4 presents the calibration model of fixed carbon content for the studied species.

In Table 4, the best results for predicting fixed carbon contents for the charcoal production were for ground wood samples. The standard normal variation transformation (SNV) was the best pre-treatment. The correlation obtained for this variable was $93 \%$, and the coefficient of determination $\left(\mathrm{R}^{2}\right)$ was 0.86 . These results corroborate those by Campos et al. (2008), who obtained a similar coefficient of determination in their study which determined the immediate chemistry of the charcoal varying $\left(\mathrm{R}^{2}\right)$ between 0.83 and 0.96 ; while Andrade et al. (2012) found a coefficient of determination $\left(R^{2}\right)$ of 0.88 , both for the prediction of the fixed carbon contents of Eucalyptus sp.

Despite representing an extremely important variable for charcoal, the ash content prediction was not successful in any of the pre-treatments for the evaluated data, which can be explained due to ash not having organic compounds in its constitution. Studies carried out by Campos et al. (2009) found that ash contents cannot be predicted through near-infrared spectroscopy in conjunction with multivariate tools.

\section{CONCLUSIONS}

Near-infrared spectroscopy presented satisfactory results in the prediction of gravimetric yield, content of volatile materials and fixed carbon for the evaluated species.

The calibrations obtained using the spectra obtained from ground samples presented the best correlations for the gravimetric yield, content of volatile materials and fixed carbon variables when compared to the spectra acquired from solid wood.

\section{ACKNOWLEDGEMENTS}

Thanks to Agricultural Research Centre for International Development -CIRAD through the PERSYST Department for the fundamental analysis and compendia for completing this work.

\section{SUBMISSION STATUS}

Received: 17 feb. 2016

Accepted: 7 nov., 2017 


\section{CORRESPONDENCE TO}

\section{Teddy Diogo Rios Terra}

Departamento de Engenharia Florestal, Universidade Federal do Tocantins - UFT, Rua Badejós, CEP 77402-970, Gurupi, TO, Brasil e-mail: trterra@uft.edu.br

\section{REFERENCES}

American Society for Testing and Materials - ASTM. E1655-05: Standard Pratices for Infrared Multivariate Quantitative Analysis. West Conshohocken: ASTM; 2000. Vol. 03.06

Andrade CR, Trugilho PF, Hein PGR, Lima JT, Napoli A. Near infrared spectroscopy for estimating Eucalyptus charcoal properties. Journal of Near Infrared Spectroscopy 2012; 20(6): 657-666. http://dx.doi.org/10.1255/jnirs.1028.

Association Française de Normalisation - AFNOR. AFNOR 1860-2: Partie 2: charbon de bois et briquettes de charbon de bois pour barbecue. Paris: AFNOR; 2000.

Campos ACM, Hein PRG, Mendes RF, Mendes LM, Chaix G. Near infrared spectroscopy to evaluate composition of agro-based particleboards. Bioresources (Raleigh, N.C) 2009; 4: 1058-1069.

Campos ACM, Hein PRG, Vieira RS, Trugilho PF, Napoli A, Chaix G. Aplicação da espectroscopia NIR na estimativa da análise química imediata do carvão vegetal. In: Simaderj - Simpósio de Ciência e Tecnologia da Madeira do Rio de Janeiro; 2008; Seropédica. Seropédica: UFRRJ; 2008.

Duca D, Pizzi A, Rossini G, Mengarelli C, Foppa Pedretti E, Mancini M. Prediction of hardwood and softwood contents in blends of wood powders using mid-infrared spectroscopy. Energy \& Fuels 2016; 30(4): 3038-3044. http://dx.doi.org/10.1021/acs.energyfuels.5b02994.

Hein PRG, Chaix G, Clair B, Brancheriau L, Gril J. Spatial variation of wood density, stiffness and microfibril angle along Eucalyptus trunks grown under contrasting growth conditions. Trees (Berlin) 2016; 30(3): 871-882. http:// dx.doi.org/10.1007/s00468-015-1327-8.

Hein PRG, Lima JT, Chaix G. Effects of sample preparation on NIR spectroscopic estimation of chemical properties of Eucalyptus urophylla S.T. Blake wood. Holzforschung, 2010; 64: 45-54.

Meder R, Stahl W, Warburton P, Woolley S, Earnshaw S, Haselhofer $\mathrm{K}$ et al. At-line validation of a process analytical technology approach for quality control of melamineurea-formaldehyde resin in composite wood-panel production using near infrared spectroscopy. Analytical and Bioanalytical Chemistry 2017; 409(3): 763-771. http:// dx.doi.org/10.1007/s00216-016-0098-4. PMid:27915369.

Nisgoski S, Klock U, Batista FRR, Schardosin FZ, Consalter R, Motta ACV. Uso do NIR na discriminação de árvores em diferentes adubações com base nos espectros da madeira e da casca. Ciência da Madeira 2016; 7(2): 100-110. http:// dx.doi.org/10.12953/2177-6830/rcm.v7n2p100-110.

Pasquini C. Near infrared spectroscopy: fundamentals, practical aspects and analytical applications. Journal of the Brazilian Chemical Society 2003; 14(2): 198-219. http:// dx.doi.org/10.1590/S0103-50532003000200006.

Ramalho FMG, Hein PRG, Andrade JM, Napoli A. Potential of near-infrared spectroscopy for distinguishing charcoal produced from planted and native wood for energy purpose. Energy \& Fuels 2017; 31(2): 1593-1599. http:// dx.doi.org/10.1021/acs.energyfuels.6b02446.

Samistraro G, Muniz GIB, Peralta-Zamora P, Cordeiro GA. Previsão das propriedades físicas do papel kraft por espectroscopia no infravermelho próximo (NIR) e regressão por mínimos quadrados parciais (PLS). Quimica Nova 2009; 32(6): 1422-1425. http://dx.doi.org/10.1590/ S0100-40422009000600011.

Schimleck L, Stürzenbecher R, Jones PD, Evans R. Development of wood property calibrations using near infrared spectra having different spectral resolutions. Journal of Near Infrared Spectroscopy 2004; 12(1): 55-61. http://dx.doi.org/10.1255/jnirs.407.

Terdwongworakul A, Punsuwan V, Thanapase W, Tsuchikawa S. Rapid assessment of wood chemical properties and pulp yield of Eucalyptus camaldulensis in Thailand tree plantations by near infrared spectroscopy for improving wood selection for high quality pulp. Journal of Wood Science 2005; 51(2): 167-171. http://dx.doi.org/10.1007/ s10086-004-0633-3.

Vale AT, Dias IS, Santana MAE. Relação entre as propriedades químicas, físicas e energéticas da madeira de cinco espécies do cerrado. Ciência Florestal 2010; 20(1): 137-145.

Viana LC, Trugilho PF, Hein PRG, Lima JT, Silva JRM. Predicting the morphological characteristics and basic density of Eucalyptus wood using the NIRS technique. Cerne 2009; 15: 421-429.

Williams P, Norris K. Near-infrared technology. 2. ed. St. Paul: American Association of Cereal Chemistry, Inc.; 2001. 